\title{
DEVELOPMENT OF ACTIVATED CARBONS FROM COAL COMBUSTION BY-PRODUCTS
}

\author{
ANNUAL TECHNICAL PROGRESS REPORT
}

Reporting Period Start Date: June 30, 1999

Reporting Period End Date: June 29, 2000

Principal Authors: Prof. Harold H. Schobert

Dr. M. Mercedes Maroto-Valer

Ms. Zhe Lu

Date of Submission: July 31, 2000

DOE Award number: DE-FG26-99FT40593

Submitting Organization: The Energy Institute

The Pennsylvania State University

405 Academic Activities Building

University Park, PA 16802-2398

Phone: (814) 8638265

Fax: (814) 8638892 


\section{Disclaimer}

This report was prepared as an account of work sponsored by an agency of the United States Government. Neither the United States Government nor any agency thereof, nor any of their employees, makes any warranty, express or implied, or assumes any legal liability or responsibility for the accuracy, completeness, or usefulness of any information, apparatus, product, or process disclosed, or represents that its use would not infringe privately owned rights. Reference herein to any specific commercial product, process or service by trade name, trademark, manufacturer, or otherwise does not necessarily constitute or imply its endorsement, recommendation, or favoring by the United States or any agency thereof. The views and opinions of authors expressed herein do not necessarily state or reflect those of the United States or any agency thereof. 


\begin{abstract}
The increasing role of coal as a source of energy in the 21 st century will demand environmental and cost-effective strategies for the use of coal combustion by-products (CCBPs), mainly fly ash containing unburned carbon. However, the carbonaceous residue in fly ash, unburned carbon (UC), is a potential precursor for the production of adsorbent carbons, since it has gone through a devolatilization process while in the combustor, and therefore, only requires to be activated. Accordingly, this research program focuses on the development of activated carbons from the unburned carbon present in fly ash.
\end{abstract}

During the present reporting period (June 30, 1999-June 29, 2000), Task 1 "Procurement and characterization of CCBPs" was initiated and samples from various combustion systems were collected. The suite assembled thus far includes samples from pulverized utility boilers with low- NOx burners and Selective Non Catalytic Reduction system, and also from an utility cyclone unit. The characterization studies showed that the sample from the cyclone unit contained the highest carbon content (LOI of $\sim 80 \%$ ), since this unit has been retrofitted with a technology to separate the unburned carbon form the fly ash. In contrast, the sample from the unit retrofitted with a Selective Non Catalytic Reduction system showed the lowest carbon content with LOI values around $2-4 \%$. The samples from the utility boilers with low-NOx burners were collected from the hot-side hoppers and present carbon contents $\sim 50 \%$. The BET $\left(\mathrm{N}_{2} 77 \mathrm{~K}\right)$ surface areas of the samples investigated were between $30-40 \mathrm{~m}^{2} / \mathrm{g}$ and the pore volume is mainly due to mesopores.

In addition, during this reporting period, also Task 2 "Development of activated carbons" and Task 3 "Characterization of activated carbons" were initiated. The investigations showed that after steam activation at $850^{\circ} \mathrm{C}$, the unburned carbon samples generated activated carbons with microporous structure and surface areas up to $443 \mathrm{~m}^{2} / \mathrm{g}$. The samples activated with steam present generally higher surface areas than those using $\mathrm{CO}_{2}$ or $\mathrm{KOH}$ pretreatment, probably due to the faster reaction rate of steam. The activation process could tailor the inherent mesoporosity of these materials into the desired porosity for a specific application, since the mesopore volume accounted for $\sim 66 \%$ of the total pore volume for the parent samples, while after steam activation the micropore volume accounted for over $60 \%$ of the total. 
$\begin{aligned} \text { Page } & \text { Pag } \\ 2 & \end{aligned}$

DISCLAIMER

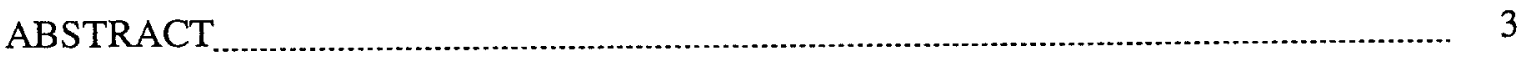

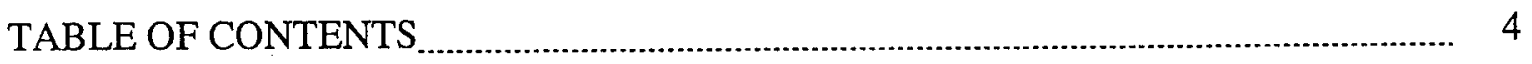

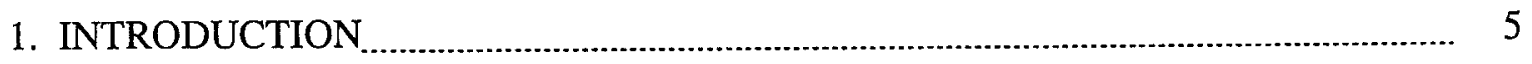

1.1. Rationale

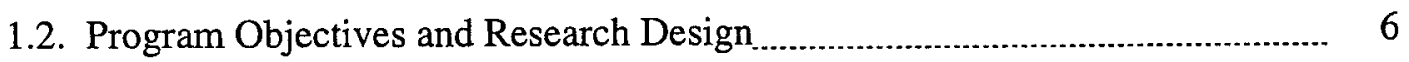

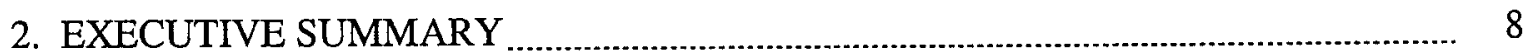

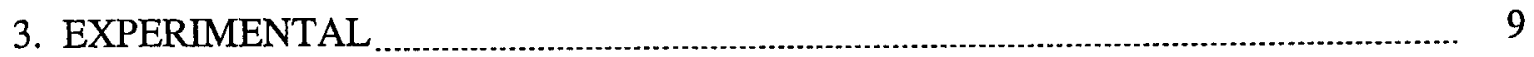

3.1. Task 1: Procurement and Characterization of CCBPs

3.2. Task 2: Development of activated carbons from unburned carbon _.................... 9

3.3. Task 3: Characterization of the produced activated carbon materials ............... 10

4. RESULTS AND DISCUSSION

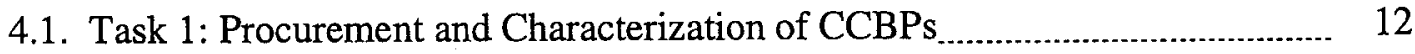

4.1.1. Loss-on-ignition (LOI) $\ldots$

4.1.2. Inherent porosity ................................................................... 12

4.2. Task 2: Development of activated carbons from unburned carbon _.................... 13

4.3. Task 3: Characterization of the produced activated carbon materials ............... 13

4.3.1. Effect of activating agent .......................................................... 13

4.3.2. Porosity development $\ldots$

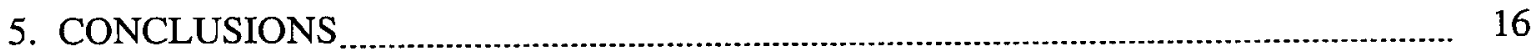

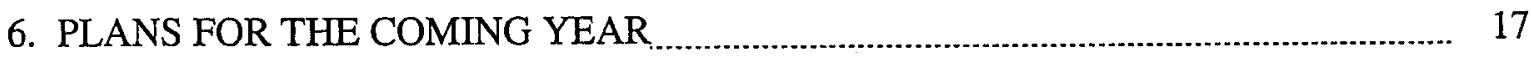

7. PUBLICATIONS RESULTING OF THIS RESEARCH PROGRAM $\ldots \ldots \ldots \ldots \ldots \ldots \ldots \ldots \ldots$

8. REFERENCES 


\section{INTRODUCTION}

\subsection{Rationale}

The US electric power industry relies heavily on the use of coal as the primary energy source. In 1997, around $90 \%$ of the total US coal production was used in coal-fired units to generate over $55 \%$ of the total electricity. ${ }^{1}$ Furthermore, coal is the most abundant fossil fuel resource in the US, and therefore it will even play an increasing role as a source of energy in the 21 st century. ${ }^{2}$ However, the use of coal for energy generation faces environmental challenges due to the emissions of pollutants such as NOx and SOx from coal combustion furnaces and such pressures will only intensify in the next century. Therefore, to guarantee a key role of coal as energy source, the conventional processes for coal utilization have to be redesigned to comply with Clean Air Act Amendments. In particular, the implementation of these regulations concerning NOx emissions is being addressed in coal combustion furnaces mainly by a combination of low-NOx burners and catalytic reduction systems. Although low-NOx burner technologies efficiently decrease the emissions level by lowering the temperature of combustion, they also reduce the combustion efficiency, resulting in an increase in carbonaceous waste product. ${ }^{3}$ In 1997, the combustion of over 900 million tons of coal generated around 75 million tons of coal combustion by-products (CCBPs), mainly fly ash containing unburned carbon. ${ }^{4}$ Due to the present lack of commercial demand for such materials, the fate of these products is mainly disposal. However, the increasingly severe regulations on disposal and the limited access to new disposal sites coupled with the subsequent increase in the cost of disposal, will force the coal and energy industry to recycle a larger amount of CCBPs. Consequently, there is a clear need to establish environmental and cost-effective strategies for the use of these carbonaceous waste products from coal combustion.

The carbonaceous residue in fly ash, unburned carbon, is a potential precursor for the production of adsorbent carbons, since it has gone through a devolatilization process while in the combustor, and therefore, only requires to be activated. The present global consumption of activated carbons is over 350,000 tons and it is estimated to rise $7 \%$ annually. ${ }^{5}$ The main reason for this expanding market is the ubiquitous use of activated carbons as adsorbent materials in a 
broad range of increasing household, medical, industrial, military and scientific applications. These range from gas-phase adsorption in household air conditioning equipment and industrial emissions control, to liquid-phase adsorption for water treatment and even gold recovery. Therefore, due to the expanding market for activated carbons, especially in applications related to environmental protection, such as air and water purification, new precursors are being sought. ${ }^{2}$ However, for these new precursors to compete effectively with conventional raw materials like coal and wood, they must be inexpensive, have a low mineral matter content and be easily converted into activated carbons. The unburned carbon in the ash furnishes satisfactorily all these conditions, since it can be easily obtained from the utility industries as a by-product, it can be beneficiated from the fly ash by commercially available techniques and it has already gone through a devolatilization process in the combustor and, therefore, only requires to be activated. Furthermore, the average price for a ton of activated carbon ranges from $\$ 500$ up to $\$ 4000,{ }^{5}$ which implies a potential 50-400 fold increase compared to the price of the ash (currently $\$ 10$ 20/ton). Therefore, the use of unburned carbon as precursor for the production of activated carbons would help the utilities to offset the cost of installing and running a beneficiation process. Accordingly, this work addresses the potential use of unburned carbon from coal combustion as precursor for the production of adsorbent carbons.

\subsection{Program Objectives and Research Design}

The overall objective of this program is to develop adsorbent materials from coal combustion by-products (CCBPs) that are mainly the unburned carbon in fly ash. In this research program, the following three tasks have been defined:

- Task 1: Procurement and characterization of coal combustion by-products. In this task, samples from different combustion processes will be collected, including pulverized, cyclone, stoker firing and fluidized-bed combustion, and the properties of this unique suite of CCBPs are extensively characterized by a wide range of analytical techniques.

- Task 2: Production of activated carbons from unburned carbon. Several routes for the preparation of activated carbons are proposed to be investigated, including physical activation with different gases, such as steam and $\mathrm{CO}_{2}$, and chemical activation, like $\mathrm{KOH}$ pretreatmement. 
- Task 3: Characterization of the properties of the activated carbon materials. In this task, the properties of the produced activated carbons are systematically characterized, especially their porous structure. This will provide information for the understanding of the mechanisms involved in the generation of activated carbon from unburned carbon and also to establish the optimum route for the production of activated materials. Moreover, the commercial applications of the resultant adsorbent carbons will be investigated to assess the marketability of these materials.

Upon completion of this research program, a novel process for the production of adsorbent materials from CCBPs will have been investigated. This will have a double environmental and economical impact, since CCBPs that are currently being disposed, can be used as precursors for the production of premium carbon products like activated carbons. 


\section{EXECUTIVE SUMMARY}

To guarantee a key role of coal as energy source, the conventional processes for coal utilization have to be redesigned to comply with Clean Air Act Amendments. In particular, the implementation of regulations concerning NOx emissions by installing low-NOx burners has resulted in an increase in carbonaceous waste product. In 1997, around 75 million tons of coal combustion by-products (CCBPs) were generated in US, mainly fly ash containing unburned carbon. Due to the present lack of commercial demand for such materials, the fate of these products is mainly disposal. However, the increasingly severe regulations on disposal and the limited access to new disposal sites coupled with the subsequent increase in the cost of disposal, will force the coal and energy industry to recycle a larger amount of CCBPs. Consequently, there is a clear need to establish environmental and cost-effective strategies for the use of these carbonaceous waste products from coal combustion.

The carbonaceous residue in fly ash, unburned carbon, is a potential precursor for the production of adsorbent carbons, since it has gone through a devolatilization process while in the combustor, and therefore, only requires to be activated. Accordingly, the overall objective of this program is to develop adsorbent materials from coal combustion by-products (CCBPs) that are mainly the unburned carbon in fly ash. In this research program, the following three tasks have been defined: Task 1 "Procurement and characterization of coal combustion by-products"; Task 2 "Production of activated carbons from unburned carbon" and Task 3 "Characterization of the properties of the activated carbon materials"

During this reporting period (June 30, 1999-June 29, 2000), the following tasks have been conducted, as scheduled in the project proposal:

- Under Task 1, samples were collected from pulverized utility boilers, including low-NOx burners and Selective Non Catalytic Reduction system, and also from an utility cyclone unit. The sample from the cyclone unit contained the highest carbon content (LOI of $\sim 80 \%$ ), since this unit has been retrofitted with a technology to separate the unburned carbon form the fly ash. In contrast, the sample from the unit retrofitted with a Selective Non Catalytic Reduction system showed the lowest carbon content with LOI values around 2-4\%. The samples from the utility boilers with low-NOx burners were collected from the hot-side hoppers and present carbon contents $\sim 50 \%$. The BET $\left(\mathrm{N}_{2} 77 \mathrm{~K}\right)$ surface areas of the samples investigated were between $30-40 \mathrm{~m}^{2} / \mathrm{g}$ and the pore volume is mainly due to mesopores. This indicated that the extensive and rapid devolatilization that coal undergoes in the combustor, seems to promote the generation of meso- and macropores.

- Under Tasks 2 and 3, the samples were physically activated, using steam and $\mathrm{CO}_{2}$, and also chemically, using $\mathrm{KOH}$ pretreatment. After steam activation at $850^{\circ} \mathrm{C}$, the unburned carbon samples generated activated carbons with microporous structure and surface areas up to 443

$\mathrm{m}^{2} / \mathrm{g}$. The samples activated with steam present generally higher surface areas than those using $\mathrm{CO}_{2}$ or $\mathrm{KOH}$ pretreatment, probably due to the faster reaction rate of steam. The activation process could tailor the inherent mesoporosity of these materials into the desired porosity for a specific application, since the mesopore volume accounted for $\sim 66 \%$ of the total pore volume for the parent samples, while after steam activation the micropore volume accounted for over $60 \%$ of the total. 


\section{EXPERIMENTAL}

\subsection{Task 1: Procurement and Characterization of Coal Combustion By-Products}

The aim of this task is to assemble a suite of CCBPs generated by different combustion technologies and to carry out a systematic characterization of the CCBPs. The samples collected have been generated in a variety of combustion processes, including: (i) pulverized utility boilers, where two samples were collected from systems retrofitted with low- NOx burners (243 and $180 \mathrm{MW}$, respectively) and one from an unit that has been retrofitted with a Selective Non Catalytic Reduction system (136 MW); and (ii) one sample collected from an utility cyclone unit (216 MW). The loss-on-ignition (LOI) contents of the fly ashes assembled were determined according to the ASTM C311 procedure. These analyses were conducted in duplicates. For fly ashes commonly derived from Eastern U.S. coals, the LOI value essentially equates to carbon content. The characterization of the inherent porosity of the samples was determined by conducting $\mathrm{N}_{2}$ adsorption isotherms at $77 \mathrm{~K}$ using a Quantachrome adsorption apparatus, as described in Section 3.3.

\subsection{Task 2: Production of Activated Carbons from Unburned Carbon}

The unburned carbon samples were physically activated, using steam or $\mathrm{CO}_{2}$, and chemically using $\mathrm{KOH}$ pretreatment. The activation experiments were carried out in an activation furnace, which consists of a stainless steel tube reactor inside a vertical tube furnace. Figure 1 shows a schematic of the activation set-up, that consists of a vertical tube furnace. Firstly, a stainless steel tube reactor, containing around 3-5 g of sample, is placed in the middle of the furnace to assure a uniform temperature zone. A thermocouple inserted in the reactor monitors the sample temperature. The furnace is then heated to the desired activated temperature, typically $850^{\circ} \mathrm{C}$. When the sample reaches the activation temperature, typically within 20 minutes, a flow of steam is introduced. For this purpose, a reservoir is used to pump water into the reactor at low flow rates $(\sim 1.2 \mathrm{~g} / \mathrm{min})$ by introducing a slight head pressure of nitrogen. The water goes through a coil inside the furnace and the steam generated enters the 
bottom of the reactor. During the activation process, liquid products and water are collected by condensation, while gases are vented off. After the desired activation period, typically around 60 minutes, the sample is quenched by flowing air in the outside of the reactor assembly. For the $\mathrm{CO}_{2}$ activation experiments, the $\mathrm{CO}_{2}$ was also introduced through the bottom of the furnace and passed a heating coil, before entering the reactor. For the chemical activation, the samples were pretreated with a $\mathrm{KOH}$ solution and then pyrolyzed under $\mathrm{N}_{2}$ in the activation furnace at $850^{\circ} \mathrm{C}$. The resultant product was then treated with $\mathrm{HCl} / \mathrm{HNO}_{3}$ to remove the activation agent. The sample was then washed with distilled water till the $\mathrm{pH}$ was about neutral.

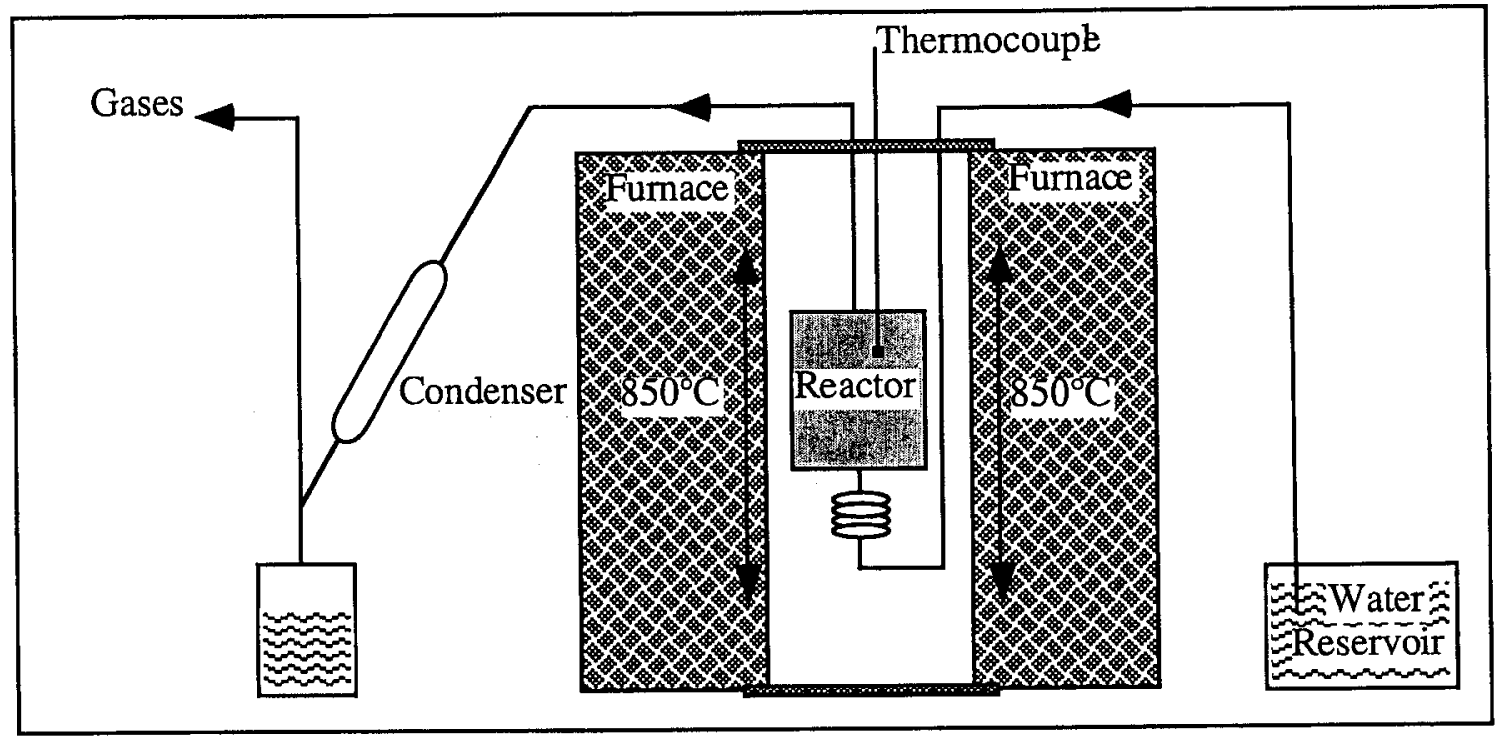

Figure 1. Schematic of the activation set-up.

\subsection{Task 3: Characterization of activated carbons}

The systematic characterization of the activated carbons produced will allow us to understand the mechanisms involved in the generation of activated carbon from unburned carbon and also to establish the optimum route for the production of activated materials. For this purpose, the porosity of the samples was characterized conducting $\mathrm{N}_{2}$ adsorption at $77 \mathrm{~K}$ using a Quantachrome adsorption apparatus. Autosorb-1 Model ASIT. The BET surface areas were 
calculated using the adsorption points at the relative pressures $\left(\mathrm{P} / \mathrm{P}_{0}\right) \quad 0.05 \sim 0.25$. The value reported were corrected to a mineral-free basis using the $6 \mathrm{~m}^{2} / \mathrm{g}$ surface area measured for a high content ash sample and the TGA-derived inorganic contents for the respective density fractions. ${ }^{6}$ The total pore volume, $V_{\text {TOr, }}$, was calculated from the amount of vapor adsorbed at the relative pressure of 0.95 . The mesopore (pores $2-50 \mathrm{~nm}$ in width) and micropore (pores $<2 \mathrm{~nm}$ in width) volumes were calculated using the $\mathrm{BJH}$ and $\mathrm{DR}$ equation, respectively). 


\section{RESULTS AND DISCUSSION}

\subsection{Task 1: Procurement and characterization of the suite of CCBPs.}

As previously described in Section 3.1., the samples collected have been produced in a variety of combustion processes, including: (i) pulverized utility boilers, where two samples were collected from systems retrofitted with low- NOx burners (243 and $180 \mathrm{MW}$, respectively) and one from an unit that has been retrofitted with a Selective Non Catalytic Reduction system (136 MW); and (ii) one sample collected from an utility cyclone unit (216 MW). A series of analysis were conducted on the above samples to characterize their properties, including loss-onignition (LOI) and porosity, as described below.

\subsubsection{Loss-on-ignition (LOI)}

The determination of the loss-on-ignition (LOI) contents was conducted according to the ASTM C311 procedure, where for fly ashes commonly derived from Eastern U.S. coals, the LOI value essentially equates to carbon content. As expected, the sample from the cyclone unit contained the highest carbon content (LOI of $\sim 80 \%$ ), since this unit has been retrofitted with a technology to separate the unburned carbon form the fly ash. In contrast, the sample from the unit retrofitted with a Selective Non Catalytic Reduction system showed the lowest carbon content with LOI values around $2-4 \%$. The samples from the utility boilers with low-NOx burners were collected from the hot-side hoppers and present carbon contents $\sim 50 \%$.

\subsubsection{Inherent porosity}

The characterization of the inherent porosity of the samples collected was carried out by conducting $\mathrm{N}_{2}$ adsorption isotherms at $77 \mathrm{~K}$ using a Quantachrome adsorption apparatus. The BET $\left(\mathrm{N}_{2} 77 \mathrm{~K}\right)$ surface areas of the samples investigated were between $30-40 \mathrm{~m}^{2} / \mathrm{g}$. Pore size distribution studies were also conducted and showed that the pore volume is mainly due to 
mesopores, with the mesopore volume accounting for over $60 \%$ of the total pore volume, where the extensive and rapid devolatilization that coal undergoes in the combustor, seems to promote the generation of meso- and macropores.

\subsection{Task 2: Development of activated carbons from CCBPs.}

As previously described in Section 3.2, the unburned carbon samples were physically activated, using steam and $\mathrm{CO}_{2}$, and chemically using $\mathrm{KOH}$ pretreatment. The effect of the activated agents was determined by calculating the solid yields and the BET surface areas, as described in the following Section.

\subsection{Task 2: Characterization of activated carbons from CCBPs.}

\subsubsection{Effect of the activating agent}

Table 1 presents the solid yields and BET surface areas (SA) for the unburned carbon samples activated under different conditions, where the suffixes $\mathrm{S}, \mathrm{C}$, and $\mathrm{K}$ stand for steam, $\mathrm{CO}_{2}$ and $\mathrm{KOH}$ activation agents, respectively.

Table 1. Pore characterization of the unburned carbon samples activated at $850^{\circ} \mathrm{C}$.

\begin{tabular}{ccccc}
\hline Sample & Activation agent & $\begin{array}{c}\text { Activation } \\
\text { time / min }\end{array}$ & $\begin{array}{c}\text { Yield } \\
\%\end{array}$ & $\begin{array}{c}\text { SA (BET) } \\
\mathrm{m}^{2} / \mathrm{g}\end{array}$ \\
\hline UC-A-S & Steam & 60 & 73 & 332 \\
UC-B-S & Steam & 60 & 55 & 443 \\
UC-C-C & $\mathrm{CO}_{2}$ & 60 & 93 & 93 \\
UC-C-K & $\mathrm{KOH}$ & 60 & 58 & 110 \\
\hline
\end{tabular}

All the samples were activated for 60 minutes at $850^{\circ} \mathrm{C}$. Despite the low particle size of the unburned carbon samples, typically $<75 \mu \mathrm{m}$, the solid yields are higher than those typically 
obtained for coals under the same conditions ${ }^{7}$, since the unburned carbon has undergone devolatilization in the combustor. The samples activated with steam present generally higher surface areas than those using $\mathrm{CO}_{2}$ or $\mathrm{KOH}$ pretreatment, probably due to the faster reaction rate of steam.

\subsubsection{Porosity development}

Figure 2 compares the meso- and micropore volume of the three precursors, UC-A, UC$\mathrm{B}$, and $\mathrm{UC}-\mathrm{C}$, and their activated samples.

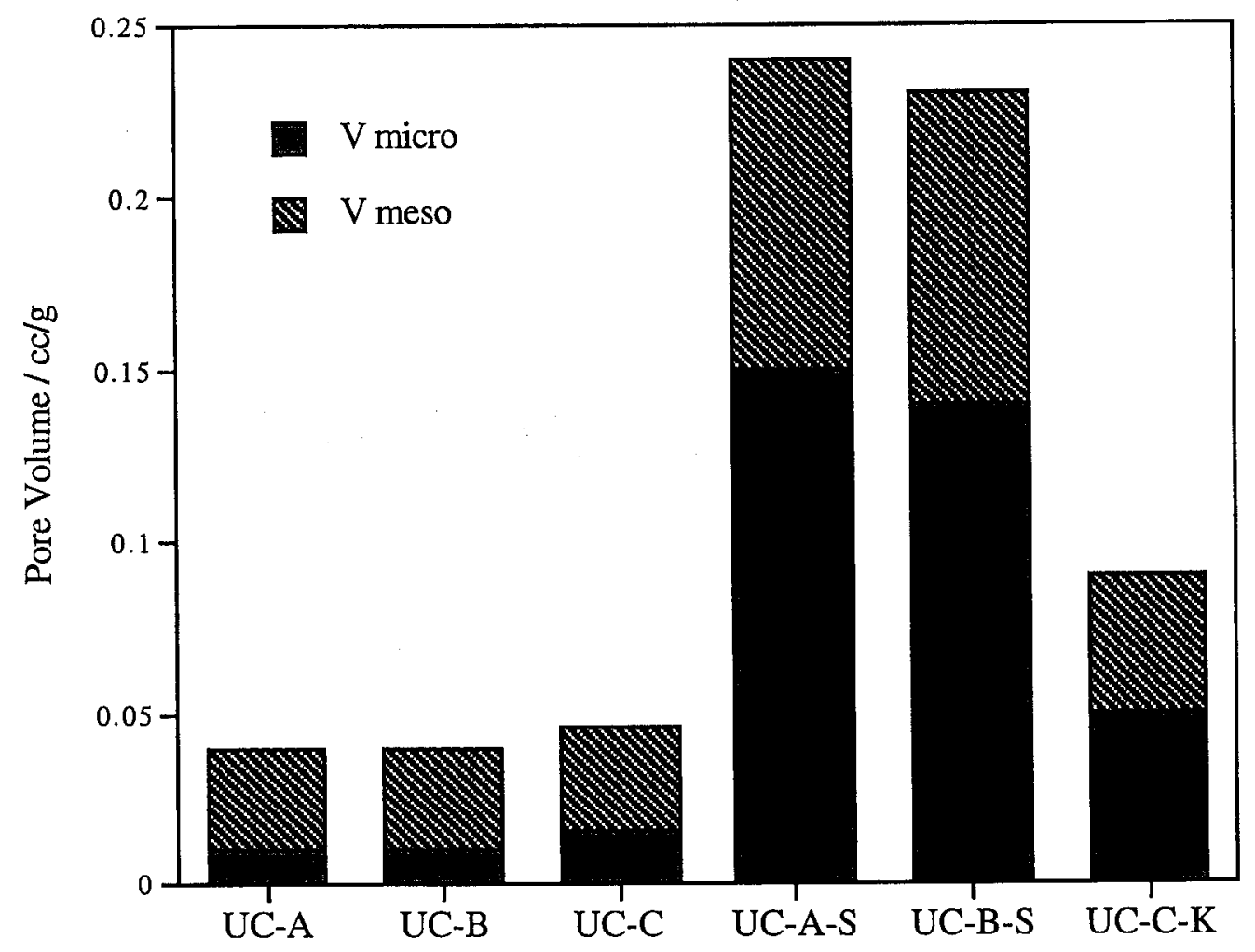

Figure 2. Distribution of the micro- and mesopore volume of the three precursors, UC-A, UC-B, and UC-C, and their activated counterparts.

All the adsorption isotherms of the parent unburned carbon samples were Type II, according to the BDDT classification, and they are typical for nonporous or macroporous adsorbents, on which unrestricted monolayer-multilayer adsorption can occur. Previous studies 
conducted by the authors on a range of fly ashes and density gradient centrifugation (DGC) concentrates have shown that the extensive and rapid devolatilization that coal undergoes in the combustor, seems to promote the generation of meso- and macropores ${ }^{8}$. Pore size distribution studies were also conducted and showed that the pore volume of the parent samples is mainly due to mesopores, with the mesopore volume accounting for over $60 \%$ of the total pore volume ${ }^{8}$. However, the steam activation process promotes the development of micropores, with the micropore volume now accounting for over $60 \%$ of the total. Pore size distribution studies and $\mathrm{CO}_{2}$ porosity measurements are now being conducted. 


\section{CONCLUSIONS}

The work reported here has investigated the activation of unburned carbons by using physical (steam and $\mathrm{CO}_{2}$ ) and chemical ( $\mathrm{KOH}$ pretreatment) methods. The solid yields obtained are higher than those typically obtained for coals under the same experimental conditions. The samples activated with steam present generally higher surface areas than those using $\mathrm{CO}_{2}$ or $\mathrm{KOH}$ pretreatment, probably due to the faster reaction rate of steam. The activation process could tailor the inherent mesoporosity of these materials into the desired porosity for a specific application, since the mesopore volume accounted for $\sim 66 \%$ of the total pore volume for the parent samples, while after steam activation the micropore volume accounted for over $60 \%$ of the total. Finally, it is envisaged that increasing the activation time will result in higher surface areas at the expenses of some solid yield, and these experiments are now underway in our laboratory. 


\section{PLANS FOR THE COMING YEAR}

The work planned for the coming year include the following tasks:

- Finalize the procurement of the suite of CCBPs. It is anticipated that this will include samples from a suspension-fired research boiler ( $2 \mathrm{MM} \mathrm{Btu/hour)} \mathrm{operated} \mathrm{by} \mathrm{The}$ Energy Institute, a stoker and a fluidized bed.

- Design a battery of tests to characterize the samples assembled. It is anticipated that these tests will include the above LOI and surface area measurements as well as optical microscopy studies.

- Continue the activation of the unburned carbon samples under a wider range of controlled operating variables in order to establish the optimum route for the generation of activated carbon materials. In addition, various modifications are being conducted in the activation system, including: installation of a HPLC pump to optimize the flow control of water during the steam activation experiments; development of a data acquisition control unit using commercial software; and scaleup of the reactor.

- Publish widely the outcome of these investigations. 


\section{PUBLICATIONS RESULTING OF THIS PROJECT}

- Harold H. Schobert, M. Mercedes Maroto-Valer and Zhe Lu, Development of Activated Carbons from Coal Combustion By-Products, 2000 University Coal Research Contractors Review Meeting, 128-130.

- Zhe Lu, M. Mercedes Maroto-Valer and Harold H. Schobert, Development of Activated Carbons from Coal Combustion By-Products, 17th Annual International Pittsburgh Coal Conference, 2000, Accepted. 


\section{REFERENCES}

1 Hong, B.D., Mining Engineering 1998, 50, 230

2 Song, C. and Schobert, H.H., Fuel 1996, 75, 724

3 Maroto-Valer, M.M., Taulbee, D.N. and Hower, J.C. Am. Chem. Soc. Division of Fuel Chemistry Preprints 1998, 43, 1014

4 Stewart. B., Proceedings 15th Annual International Pittsburgh Coal Conference 1998, Paper 6-1, 139.pdf (CD-ROM publication).

5 Derbyshire, F., Jagtoyen, M., and Thwaites, M., In: Porosity in Carbons (Ed. Patrick, J.W.), Edward Arnold, London, 1995

6 Maroto-Valer, M.M., Taulbee, D.N., Hower, J.C. and Schobert, H.H. in Proceedings 1999 International Ash Utilization Symposium, 1999, 188-194.

7 Maroto-Valer, M.M., Taulbee, D.N. and Schobert, H.H., 1999, Prepr. Am. Chem. Soc. Fuel Division, 44, 101.

8 Maroto-Valer, M.M., Taulbee, D.N. and Hower, J.C., 2000, Fuel, In Press. 